\title{
Efficacy of different endodontic procedure with post-operative pain and Quality of Life (QoL) using (OHIP-14).
}

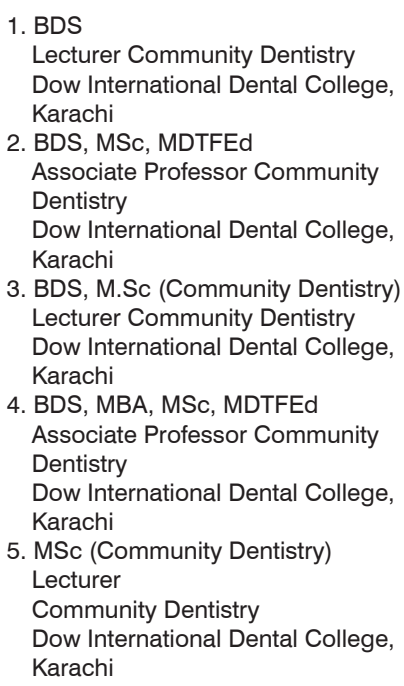

3. BDS, M.Sc (Community Dentistry) Lecturer Community Dentistry Dow International Dental College, Karachi

4. BDS, MBA, MSc, MDTFEd

Associate Professor Community Dentistry

Dow International Dental College, Karachi

5. MSc (Community Dentistry) Lecturer

Community Dentistry

Dow International Dental College, Karachi

Correspondence Address:

Dr. Eisha Abrar

Department of Community Dentistry DIDC, Mehmodabad Chanesar Goth Karachi.

eshaabrar92@gmail.com

Article received on:

05/03/2020

Accepted for publication:

25/06/2020

\section{INTRODUCTION}

Quality of life (QoL) is the degree to which individuals enjoy their life. ${ }^{1}$ Two major concerns of dental patients regarding root canal therapy is usually time and pain. ${ }^{2}$ Pain is considered as one of the most common reason for which a patient visits a dentist. ${ }^{3}$ However, it is one of the collective factor for their refusal to undergo treatment. ${ }^{4}$ Primary objective of an endodontic treatment is to eliminate microorganism from the canal system. ${ }^{5}$ Post endodontic pain can be a complication due to operator technique, type of endodontic system used and form of irrigation. ${ }^{6}$ The success of conventional root canal therapy accounts for 70 to $95 \% .^{7}$ However, there are a large number of potential issues that may arise with this type of conventional canal therapy i.e., Improper canal cleaning resulting in pain, swelling and compromising QoL leading to destress. ${ }^{8}$
In Hand protaper methods the NiTi (NickelTitanium) framework is widely used. ${ }^{9}$ Hand NiTi instruments gives better hand control to both amateur and specialist as the cutting and forming velocity can be controlled by the user and this gives more certainty in canal preparation. ${ }^{10} \mathrm{Hand}$ Pro-Taper NiTi instruments have multiple and dynamic decreases (2-19\%), triangular-convex cross area with sharp cutting edges ${ }^{11}$, and a variable helical edge with non-cutting tip. ${ }^{12}$ Root canal instruments of this cross-sectional design claim to cut dentine more effectively. ${ }^{13}$

An instrument used to evaluate personal satisfaction in connection to oral issue is the Oral Health Impact Profile (OHIP). ${ }^{14}$ The model is used to recognize seven conceptual dimensions of impact, namely functional limitation, physical pain, psychological discomfort, physical disability, psychological disability, social disability 
and handicap. ${ }^{15}$

Quality of life and satisfaction after root canal treatment has already been assessed in Canadian population. In the same study Dugas et all ${ }^{16}$., observed that patients who were treated by endodontists displayed high level of satisfaction improving quality of life. Similar study conducted by Hamasha and Hatiwsh ${ }^{17}$ revealed that $90 \%$ of the patients showed improvement in their oral health impact profile (OHIP) after endodontic treatment but there was no significant difference in (OHIP) amongst patients treated by different level of dental care providers.

To our knowledge from indexed literature existing evidence shows quality of life after canal therapy using hand protapers is scarce and limited. The aim of the present investigation was to evaluate the effect of endodontic illness prior and after treatment through OHIP 14. It is hypothesized that conventional canal therapy will result in better postoperative patient satisfaction compared to hand protapers.

\section{MATERIAL \& METHODS}

A longitudinal study was conducted to evaluate the effect of root canal procedures on oral health impact profile of patients. It was conducted at Dow International Dental College and Dr Ishrat UIIbad Khan Institute of Oral And Health Sciences, Karachi, Pakistan. Adults in the age range of 18-50 years attended both institutes OPDS for routine root canal treatment would be eligible to participate.

Participants included are patients with root canal advised on single rooted premolar also systemically healthy, mentally stable and legally eligible of signing the consent form. Patients with diabetic mellitus, blood disorders, pregnancy and those who are taking pain killers for any other reason were excluded from the study. Participant were informed about the objective of the study and consent was taken from them to participate. Assurance was given that this data will be kept confidential and only be used for scientific purpose
A convenient sampling of adult patients who were referred from the diagnostic department of the institution for root canal treatment in four different categories. Study started from March 2019 till September 2019 this led to a total of 180 patients. Out of which 5 patients did not attend the second visit and 6 patients did not attend the third visit. After this follow up loss, 169 patients were participated completely. Two types of treatments were considered for these patients, manual protaper RCT and conventional RCT. Out of these 169 patients, 55 were treated by house officers through manual protapers root canal method, 37 patients were treated by house officers through conventional root canal method and this makes the total of 92 patients being treated by house officers. Post graduate trainees treat 77 patients in total, out which 39 patients through manual protapers and the rest by conventional root canal method. 94 patients underwent manual protaper RCT and 75 underwent conventional RCT. There were 3 visits for all 4 categories.

Period was one week between each appointment. Sodium hypochlorite was used as irrigant because all treatment was primary and nonsurgical. Gutta percha was used as a root canal filling, filled through lateral compaction technique. Access cavity was filled with composite resin restoration.

Study instrument was a structured questionnaire, there were four part in the questionnaire patients personal and demographics information (age, gender, and contact number), operator, type of endodontic treatment and Oral health impact profile instrument OHIP 14.

All patients were prescribed with brufen and Panadol and were asked to take medication if they feel pain after the treatment.

Patient was then called after 3 days to ask about the post-operative pain and treatments impact on oral health related quality of life.

Data analysis was done using SPSS*20 software. Various statistical tests were applied in accordance with need. 


\section{Tooth Preparation}

\section{Group 1a}

Preparation was done by house officers through conventional method using Gates Glidden were used to access and to enlarge coronal orifice and also used for the preparation for the coronal and middle third of canal. K files from no. 10 to 45 in sequential order were used to prepare the apical part.

\section{Group 1b}

Preparation was done by postgraduate trainee through conventional method using Gates Glidden were used to access and to enlarge coronal orifice and also used for the preparation for the coronal and middle third of canal $\mathrm{K}$ files from no. 10 to 45 in sequential order were used to prepare the apical part.

\section{Group 2a}

Preparation was done by house officers using hand protaper hand files were used to prepare specimens in a crown down manner using gentle in and out motions in accordance with manufacturer's instruction.

S1 and S2. F1, F2, F3, sequentially used to working length for finishing apical one third of canal.

\section{Group 2b}

Preparation was done by postgraduates using hand protaper hand files were used to prepare specimens in a crown down manner using gentle and out motions in accordance with manufacturer's instruction.

S1 and S2. F1, F2, F3, sequentially used to working length for finishing apical one third of canal.

\section{RESULTS}

Of the total 169 patients, the mean age of $34.15(\mathrm{SD} \pm 9.873)$. Out of $169,86(50.9 \%)$ were female and $83(49.1 \%)$ were males. They were thoroughly examined before their root canal treatment to find out their pulp status, 124 patients were diagnosed for irreversible pulpits and 45 had pulp necrosis. After treatment, 85 were experiencing post-operative pain and had taken medicines for it, however 84 patients had no post-operative complains regarding pain.

There is a significant association existing between the type of treatment provided to the patient and post-operative pain. Patients who underwent manual protaper RCT felt less pain as compared to those treated with conventional RCT. $(p=0.00)$.

We also found the association between the operator and post-operative pain, there was a significant association existing between postoperative pain and operator as there is more pain in patients who were treated by house officer $(p=0.000)$.

We also found the association between the operator and post-operative medication, there was a signification association existing between consumption of medication in patients who were treated by house officers. $(p=0.001)$.

There is a significant difference between before and after treatment in quality of life (OHIP 14). Their oral health impact profile was improved after the endodontic treatment. $(P=0.000)$

There is no association between age and postoperative medication intake $(p=0.069)$

\section{DISSCUSSION}

Interest has been developed to understand the impact of oral diseases on quality of life also there has been impact of endodontic treatment provided to the patient on the oral health related quality of life..$^{18}$ The present study is conducted to expand our knowledge regarding different files system and its impact on QoL after root canal therapy, when we reviewed the current literature most of the discussion was on the tooth loss impact on quality of life ${ }^{19}$, few discussed about the impact of endodontic treatment on QoL. ${ }^{17}$ Result of present study showed that patients treated by hand protaper suffered less pain after therapy so we reject the hypothesis that conventional canal therapy will result in better postoperative patient satisfaction compared to hand protapers.

The oral health related quality of life was assessed through OHIP. 


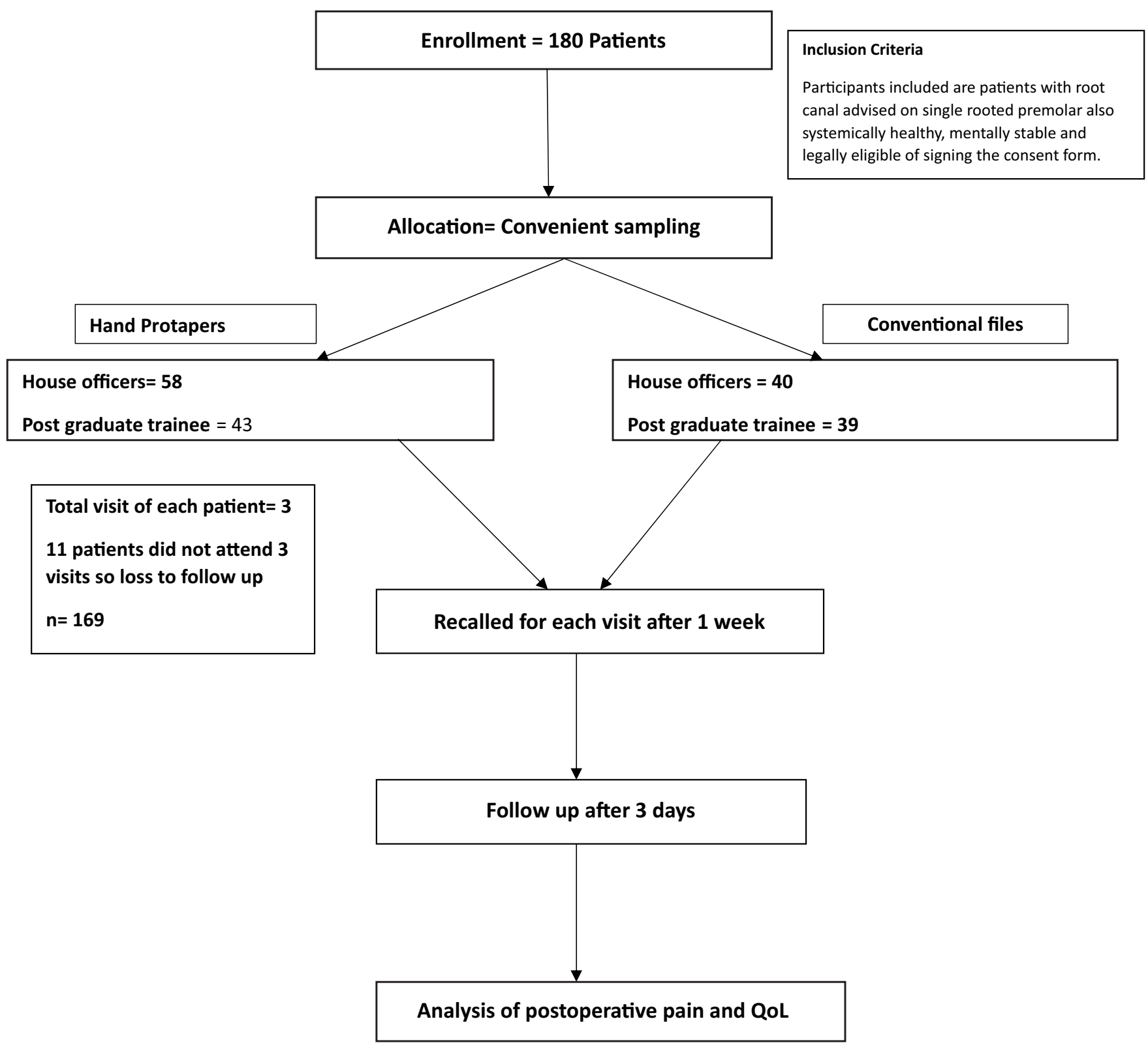

Figure-1. Flow diagram displaying study design

It is considered as a sensitive tool, it not only help practitioners to assess the oral health of the patients but also help researcher to understand the perceived needs of the patients. ${ }^{20}$ For this it has drawn the attention of research workers on quality of life. ${ }^{21}$ Consequently, it has widely been used by the scholars in the field of oral medicine to evaluate the effect of different therapeutic methods on quality of life. ${ }^{22}$

A randomized control trial was done in 2012 in which postoperative pain was checked after giving treatment by conventional files and mechanical glide path files. In both the groups, there was a significant difference in analgesic consumption, the intake of analgesics was higher in K-files (P-value of 0.01 ) similarly in this study postoperative pain was higher in conventional files group. ${ }^{1}$ In this context techniques using rotational movements result in less extrusion of apical debris than the file systems which used push and pull movements. ${ }^{23}$

The sum improvement scores of the different 
categories regarding OHIP-14 were examined. The high mean score values and limited 'flooring effect' aftergiving endodontic treatment suggested that the QoL was influenced by the endodontic treatment. Pei Liu et al in his study had significant changes in OHIP-14 score after conventional endodontic treatment $(\mathrm{P}<0.001)$ like in this study the score also gets better $(P<0.000)$. In 2013 a study was conducted which showed higher rate of satisfied patient who got their treatment by specialist and graduate students compared to treatment provided by undergraduate students $(P<0.005)$. Likewise, we had the same result with significant patient satisfaction who got their treatment from post graduate compared to house officer. $^{24}$

As result shows that there is significant difference in post-operative pain after the treatment from house officers no matter what type of treatment is given so it is concluded that house officers required more training and skills as compared to the postgraduates. It is also recommended that frequent brain storming and skill polishing activities like journal clubs, presentations and interactive sessions should be arranged during house job or internship phase to make them a strong part of dental fraternity. ${ }^{25}$ The limitation of the study was small sample size and short duration of the study.

\section{CONCLUSION}

Effect of root canal therapy on QoL is apparent in both the groups. Experience and training level impacts improvement as the postoperative pain complaints after getting treatment from post graduate trainee was significantly less.

Copyright@ 25 June, 2020.

\section{REFERENCES}

1. Van Leeuwen M, Husson O, Alberti P, Arraras Jl, Chinot $\mathrm{OL}$, Costantini $\mathrm{A}$, et al. Understanding the quality of life (QOL) issues in survivors of cancer: towards the development of an EORTC QOL cancer survivorship questionnaire. Health and quality of life outcomes. 2018; 16(1):114.

2. Martins J, Ordinola $\square$ Zapata R, Marques D, Francisco $H$, Caramês J. Differences in root canal system configuration in human permanent teeth within different age groups. Int. Endod. J. 2018; 51(8):931-41.
3. Chybowski EA, Glickman GN, Patel Y, Fleury A, Solomon $\mathrm{E}, \mathrm{He} \mathrm{J}$. Clinical outcome of non-surgical root canal treatment using a single-cone technique with Endosequence bioceramic sealer: $A$ retrospective analysis. J. Endod. 2018; 44(6):941-5.

4. Alfawaz $H$, Alqedairi A, Alkhayyal AK, Almobarak AA, Alhusain MF, Martins JN. Prevalence of C-shaped canal system in mandibular first and second molars in a Saudi population assessed via cone beam computed tomography: A retrospective study. Clin. Oral Investig. 2019; 23(1):107-12.

5. Al-Zaka IM, Atta-Allah AA-A, Al-Gharrawi HA, Mehdi JA. The effect of different root canal irrigants on the sealing ability of Bioceramic sealer. Mustansiriya Dent J. 2018; 10(1):1-7.

6. Eyüboğlu TF, Özcan M. Postoperative pain intensity associated with the use of different nickel-titanium shaping systems during single-appointment endodontic retreatment: A randomized clinical trial. 2019.

7. Garcia-Font M, Durán-Sindreu F, Morelló S, Irazusta $S$, Abella F, Roig $M$, et al. Postoperative pain after removal of gutta-percha from root canals in endodontic retreatment using rotary or reciprocating instruments: A prospective clinical study. Clin. Oral Investig. 2018; 22(7):2623-31.

8. Cormio C, Caporale F, Spatuzzi R, Lagattolla F, Lisi A, Graziano G. Psychosocial distress in oncology: Using the distress thermometer for assessing risk classes. Support. Care Cancer. 2019; 27(11):4115-21.

9. Del Fabbro M, Afrashtehfar KI, Corbella S, ElKabbaney A, Perondi I, Taschieri S. In vivo and in vitro effectiveness of rotary nickel-titanium vs manual stainless steel instruments for root canal therapy: Systematic review and meta-analysis. J Evid-Based Dent Pr. 2018; 18(1):59-69.

10. Çanakçi BC, Ustun Y, Er O, Sen OG. Evaluation of apically extruded debris from curved root canal filling removal using $\mathbf{5}$ nickel-titanium systems. J. Endod. 2016; 42(7):1101-4.

11. Moyin S, Punathil S, Pulyodan MK, Thayil S, Mohan $A$, Valsan D. An ex vivo evaluation of antimicrobial efficacy of root canal preparation with hand K-files, hand Pro Taper, and Pro Taper rotary files. J. Pharm. Bioallied Sci. 2019; 11(Suppl 2):S305.

12. Kırıcı D, Çolak Topçu M, Karataş E. Comparison of the effect of different glide path $\mathrm{Ni}-\mathrm{Ti}$ rotary systems on the formation of dentinal crack on curved root canals. Turkish Endo J (TEJ). 2017; 2(1):1-4. 
13. Cheema J, Gupta AK, Minocha A. Comparison of dentinal cracks after root canal preparation with hand files and protaper NEXT, HYFLEX EDM, K3 XF and twisted rotary files. J Adv Medi Dent Sci Res. 2018; 6(5):30-5.

14. Mary AV, Mahendra J, John J, Moses J, Ebenezar AR, Kesavan R. Assessing quality of life using the oral health impact profile (OHIP-14) in subjects with and without orthodontic treatment need in chennai, tamil nadu, India. Journal of clinical and diagnostic research: JCDR. 2017; $11(8): Z C 78$.

15. Pelo S, Gasparini G, Garagiola U, Cordaro M, Di Nardo F, Staderini E, et al. Surgery-first orthognathic approach vs traditional orthognathic approach: Oral healthrelated quality of life assessed with 2 questionnaires. Am. J. Orthod. Dentofacial Orthop. 2017; 152(2):250-4.

16. Eliyas S, Briggs P, Harris I, Newton J, Gallagher J. Development of quality measurement instruments for root canal treatment. Int. Endod. J. 2017; 50(7):65266.

17. Antunes LS, Souza CR, Salles AG, Gomes CC, Antunes LA. Does conventional endodontic treatment impact oral health-related quality of life? A Systematic Review. European Endod J. 2018; 3(1):2-8.

18. Bhaisare A, Patil A, Warhadpande M, Kalbande A. Evaluation of Oral Health Related Quality of Life and Satisfaction Outcome of Endodontic Treatment in Central India-A Cross Sectional Study. IOSR-JDMS. 2017;16(6):43-50. DOI: 10.9790/0853-1606054350
19. Pasqualini D, Corbella S, Alovisi M, Taschieri S, Del Fabbro M, Migliaretti $\mathrm{G}$, et al. Postoperative quality of life following single $\square$ visit root canal treatment performed by rotary or reciprocating instrumentation: A randomized clinical trial. Int. Endod. J. 2016; 49(11):1030-9.

20. Neelakantan P, Liu P, Dummer PM, McGrath C. Oral health-related quality of life (OHRQoL) before and after endodontic treatment: A systematic review. Clin. Oral Investig. 2019:1-12.

21. Yavari HR, Jafari F, Jamloo H, Hallaj-Nezhadi S, Jafari S. The effect of submucosal injection of corticosteroids on pain perception and quality of life after root canal treatment of teeth with irreversible pulpitis: A Randomized Clinical Trial. J. Endod. 2019; 45(5):47782.

22. Husain FA, Tatengkeng F. Oral health-related quality of life appraised by OHIP-14 between urban and rural areas in Kutai Kartanegara Regency, Indonesia: Pilot pathfinder survey. The open Dent J. 2017; 11:557.

23. Shahi S, Asghari V, Rahimi S, Lotfi M, Samiei M, Yavari H, et al. Postoperative pain after endodontic treatment of asymptomatic teeth using rotary instruments: A randomized clinical trial. Iranian Endod J. 2016; 11(1):38.

24. Khasnis SA, Kar PP, Kamal A, Patil JD. Rotary science and its impact on instrument separation: $A$ focused review. Journal of conservative dentistry: JCD. 2018; $21(2): 116$.

25. Sarkis-Onofre R, Fergusson D, Cenci MS, Moher D, Pereira-Cenci T. Performance of post-retained single crowns: A systematic review of related risk factors. J. Endod. 2017; 43(2):175-83.

\begin{tabular}{|c|c|c|c|}
\hline \multicolumn{4}{|c|}{ AUTHORSHIP AND CONTRIBUTION DECLARATION } \\
\hline Sr. \# & Author(s) Full Name & Contribution to the paper & Author(s) Signature \\
\hline 1 & Eisha Abrar & Community Dentistry/DIDC. & Eshactarar \\
\hline 2 & Qaiser Ali Baig & Community Dentistry/DIDC. & $\begin{array}{l}\text { qaisat ali baig } \\
\text { Mhasyam }\end{array}$ \\
\hline 3 & Maryam & Community Dentistry/DIDC. & Ashar Aflag \\
\hline 4 & Ashar Afaq & Community Dentistry/DIDC. & Wajiha Anzan \\
\hline 5 & Wajiha Anzar & Community Dentistry/DIDC. & Wh \\
\hline
\end{tabular}

